\title{
Older people's views of advice about falls prevention: a qualitative study
}

\author{
L. Yardley ${ }^{1, *}$, M. Donovan-Hall ${ }^{2}$, K. Francis ${ }^{1}$ and C. Todd ${ }^{3}$
}

\begin{abstract}
The aim of this study was to gain an understanding of older people's perceptions of falls prevention advice, and how best to design communications that will encourage older people to take action to prevent falls. Focus groups and interviews were carried out with 66 people aged 61-94 years recruited from a variety of settings, using falls prevention messages to stimulate discussion. Thematic analysis revealed that participants interpreted 'falls prevention' principally as meaning hazard reduction, use of aids and restriction of activity. Only one participant was aware that falls risk could be reduced by carrying out exercises to improve strength and balance. Falls prevention advice was typically regarded as useful in principle but not personally relevant or appropriate. Advice about falling was often depicted as common sense, only necessary for older or more disabled individuals, and potentially patronizing and distressing. Our findings suggest that older people do not reject falls prevention advice because of ignorance of their risk of falling, but because they see it as a potential threat to their identity and autonomy. Messages that focus on the positive benefits of improving
\end{abstract}

\footnotetext{
${ }^{\mathbf{1}}$ School of Psychology and ${ }^{\mathbf{2}}$ School of Health Professions and Rehabilitation Sciences, University of Southampton, Highfield, Southampton SO17 1BJ, UK and ${ }^{3}$ School of Nursing, Midwifery and Social Work, University of Manchester, Manchester M13 9PL, UK

*Correspondence to: L. Yardley.

E-mail: l.yardley@soton.ac.uk
}

balance may be more acceptable and effective than advice on falls prevention.

\section{Introduction}

Preventing falls in later life is a key public health priority. Around one-third of community dwellers aged $>65$ years fall each year, and falls and fear of falling are associated with increased anxiety and depression, decreased activity and mobility, reduced social contact, higher medication use and increased dependence on medical and social services and informal carers [1-6]. Falls contribute to over half of the hospital admissions for accidental injury, particularly hip fracture [7]. Currently, most older people enter falling prevention programmes after they have fallen, by which time it may be too late to avoid serious consequences, since half of those with hip facture never regain their previous level of functioning and one in five die within 3 months [8].

Randomized controlled trials have shown that the risk of falling can be significantly reduced by prevention programmes, especially interventions that include muscle strengthening and balance training exercises [9-12]. However, these interventions can only prove effective at a population level if participation rates are high. Uptake rates for falls prevention interventions in the community are typically $<50 \%[13,14]$ and are often as low as $10 \%[15,16]$. This suggests that there may be considerable reluctance on the part of older people to take part in these programmes.

There are a number of quite different reasons why older people might reject invitations to undertake falling prevention measures. Some people 
may reject the idea that they are 'at risk' because they are optimistic about their capabilities. Some may feel at risk but nevertheless deny publicly that they might fall, because they feel that to admit that they are at risk could undermine their status as competent and independent, and entail accepting a stigmatizing identity as old and frail [17, 18]. Conversely, some people may accept that they are at risk but feel that nothing can be done to reduce the risk [19].

Some older people may believe that they are at risk and that falling prevention measures can be effective, but nevertheless consider the negative consequences of undertaking these measures to outweigh the potential benefits. If health care measures threaten personal autonomy and identity, then the risk to health from falling may be considered a less immediate threat [20]. Research has shown that older people fear falling and restrict their activity not simply to avoid physical consequences such as injury and loss of independence, but because they are concerned about the social consequences of falling for self-image and self-confidence-for example, the embarrassment of being seen to lose control [6]. Paradoxically, falling prevention measures may themselves have precisely the negative social consequences of falling that many older people fear. The need to attend falling prevention classes, make safety modifications in the home, wear protective clothing or use mobility aids, may be viewed as announcing the transition to old age, dependence and further decline [21].

It is all too easy for communications about falling prevention to inadvertently fuel any of these negative attitudes. There has been no previous research into reactions to health promotion messages, although previous studies have investigated related topics, such as older people's perceptions of falling (e.g. [17]) and of falls rehabilitation programmes (for a review, see [22]). The aim of this study was to gain an understanding of older people's experiences and perceptions of specific advice about falling prevention, in order to establish what features of communications about falling risk and prevention are perceived as helpful and acceptable and which may provoke negative reactions.

\section{Methods}

\section{Focus groups and interviews}

Focus groups lasting 60-90 min were employed to facilitate discussions which explored previous experiences of communications regarding falling (in the media, from health professionals, among family and friends, other communications and interactions). To stimulate further discussion, examples of health promotion messages about falling prevention were summarized from existing materials and presented on cards in large print (the original materials were presented in the early focus groups, but caused reading difficulties that disrupted conversation). One set of cards presented key sentences that summarized each page of the widely used leaflet 'Avoiding slips, trips and broken hips' produced by the UK Department of Trade and Industry in conjunction with the charity 'Help the Aged'. Cards also summarized key messages from leaflets two of the authors had produced in collaboration with Help the Aged [23] that explained the benefits of strength and balance training for falls risk reduction, and for improving mobility and confidence in balance.

To ensure inclusion of people unable to participate in focus groups because of disability, and to elicit personal views that might not be disclosed in a group setting, we also carried out one-to-one semi-structured interviews in the homes of participants, using the same questions and materials as in the focus groups.

\section{Participants}

A total of 66 people aged between 61 and 94 years were recruited from sheltered accommodation (31) (i.e. housing for independently living older people that provides varying degrees of support), church groups (12), retirement and senior citizen clubs (11), leisure centres (9) and the local community (3). We sought community-dwelling participants from diverse settings in order to ensure representation of healthy and frail men and women with a wide age range and living in very different circumstances (see Table I for participant characteristics). 
Table I. Characteristics of the participants

\begin{tabular}{llrl}
\hline & Participants & Men & Women \\
\hline $\begin{array}{l}\text { Data collection method } \\
\quad\end{array}$ & 45 & 10 & 35 \\
$\quad$ Focus group & 21 & 8 & 13 \\
$\quad$ Interview & & & \\
Age group & 27 & 15 & 15 \\
$\quad$ 61-74 years & 39 & 33 & 33 \\
75-94 years & & & \\
Falls in the past year & 33 & 11 & 22 \\
$\quad$ None & 18 & 5 & 13 \\
$\quad$ One & 15 & 2 & 13 \\
$\quad$ Two or more & & & \\
\hline
\end{tabular}

Consequently, we drew on sheltered accommodation provision for people with differing health and socio-economic profiles (e.g. largely independent versus closely monitored, means-tested charity provision versus high-cost privately purchased provision). Initially, our written and oral advertisements invited participation from anyone who was willing to give their personal opinion on advice on falls prevention for older people. However, we discovered that it was extremely difficult to persuade younger and fitter people to take part in discussions of falling, and so to recruit people from these categories we were obliged to alter the focus of our recruitment materials and questions to ask initially about opinions about health promotion and 'balance training' for retired people, only introducing the issue of falling prevention later in the interview.

\section{Procedure}

Prior approval for the study was obtained from the University of Southampton School of Psychology Ethics Committee. Focus group sizes varied between three and six participants, and were carried out at the centres from where participants were recruited. One researcher led the discussion, while another researcher attended to practical matters (e.g. completion of consent forms) and recorded the order of speakers to assist later transcription. Interviews were carried out in participants' homes. The format of both interviews and focus groups was that firstly the researcher reiterated the aims and groundrules of the study (e.g. confidentiality, freedom of expression) and the participants completed consent forms. The discussions were then carried out, and finally participants completed forms giving personal details and were offered a small gift as a token of appreciation for their participation. All focus groups and interviews were audiotaped and fully transcribed.

\section{Analysis}

A thematic analysis [24] was carried out, employing the following steps. First the researchers read and re-read the transcripts and discussed the best approach to the data. It became clear at this stage that because of the relatively large size of the data set, simple immersion in the material was not sufficient to allow us to identify inductive codes and themes that were sufficiently comprehensive but also specific to categorize all the data. Consequently, one researcher initially condensed the data by summarizing all the opinions expressed in each transcript, providing an index to the passage in the transcript on which each summary statement was based so that the exact meaning and context of each statement could be checked at later stages of the analysis. It was then possible to identify a set of themes that the researchers agreed could classify all the statements into the categories and subcategories reported in Table II. Having done this, we noted how widespread each view appeared to be in this sample, so that this could be reported qualitatively in the text. No systematic differences were observed between views expressed in focus groups and interviews, and so these data were pooled for the analysis. Constant comparison, a technique drawn from grounded theory [25], was used to examine the circumstances under which particular opinions were expressed (e.g. relating these to the age and falling status of participants, and to other views expressed by the same participants). We also tested the generality of observed themes and patterns by explicitly searching for disconfirming data (e.g. instances where receiving falls advice were mentioned or where unequivocally enthusiastic views of falls prevention advice were offered). Finally, all researchers critically reviewed the emerging analysis and made suggestions for amendment or elaboration. 
Table II. Themes and subcategories identified after summarizing views expressed in each transcript

Previous experience of falls prevention advice Denied receiving advice about falls prevention

Mentioned advice relevant to reducing risk (e.g. slow down, take care, home modifications)

Positive statements about advice

The advice is helpful (e.g. it is good to acknowledge and talk about the problem, new tips are given, useful reminder to exercise)

Qualifications

The advice is appreciated just as information, will not be acted on

The advice is useful for others (e.g. older, fallers, disabled, fearful)

The advice is not suitable for everyone, and needs to be modified to suit individual circumstances

Negative statements about advice

The advice is common sense, risks are already known from experience

The advice is authoritarian and patronizing in tone The advice makes older people responsible for preventing falls, but falls are inevitable, accidents due to chance The advice can make you feel anxious, depressed

Recommendations for improving advice

Promote and support exercise as constructive means of falls prevention

Incorporate into general health promotion activities, ensure enjoyable

Frame advice as tentative, positive suggestions and give explanations/rationale

\section{Results}

\section{Perceptions of available falls prevention advice}

When asked about what they had heard concerning falls prevention (in the media, from health professionals or from friends and relatives), almost everyone flatly denied having received any previous communications about the topic. Nevertheless, during the subsequent discussions it became clear that some advice had been received from these sources, chiefly concerning the need to slow down, limit activities, take care and sometimes reduce risks at home. The concept of 'falls prevention' was linked by participants solely to hazard reduction approaches and the use of mobility aids. A large number of participants already had a modified

home environment (e.g. with rails, easily reached shelving or alarms). In contrast, only one participant mentioned being aware that balance could be improved and falls risk reduced by appropriate forms of exercise.

\section{Perceptions of falls prevention messages presented}

It's good advice-BUT ...

On the whole, participants expressed positive attitudes towards provision of advice on the topic of falls prevention, and felt that there was currently insufficient information about it. Messages explaining the positive benefits of exercise for balance and mobility were mainly welcomed. Participants related this advice to their own lives, concurred with the benefits, gave examples of the relevant activities they already undertook and often spontaneously considered whether they could undertake more of these activities.

Responses to messages that were explicitly aimed at falls prevention were more mixed. Many people said that they felt this advice was useful, and contained valuable suggestions. Some people commented that warning about falls risk might play a necessary role in adjustment to ageing, reminding older people of the need to adapt their activities. A group of women aged 78-95 years living in sheltered accommodation welcomed the opportunity to share their experiences:

I think this [focus group] has done us all good because a lot of us don't know the other person has this problem, so being together helps doesn't it?

These participants talked about how the falling prevention material offered them opportunities to overcome the feelings of anxiety and helplessness associated with their awareness of falling risk:

I think it would be helpful if someone knows what you should do and what you shouldn't do.

I think it would give me more confidence of building up your balance if I read this [leaflet about improving balance] now. I think it would give me more confidence when I'm out. 
But despite general endorsement of the value of falls prevention advice, approval of falls prevention messages was frequently qualified in various ways. Often the advice was treated as good in principle, but not necessarily to be put into practice. One member of a sheltered accommodation group aged 74-87 years summed this attitude up:

You get a little booklet, and its very attractive and you ... read it all and you find it interesting and then you put it away and you forget it.

or as another participant (female, 67, non-faller) put it:

It's all good. I mean its good advice, yes, excellent, I agree. I doesn't mean to say I do it all but I agree.

Sometimes a mixed attitude reflected an acceptance of certain components of the advice as appropriate for themselves, but rejection of other components of the advice as unsuitable in their case, because of their personal circumstances or preferences. Participants explained that they had lifestyle-related reasons for consciously choosing to use eyewear, footwear or furnishings that they admitted might carry some degree of risk, or for rejecting advice that they believed was incompatible with other important objectives, such as convenience and practicality, or might compromise more highly prioritized goals, such as retaining their independence or femininity. For example, the idea of wearing hip protectors was rejected by women aged 74,78 and 88 years who had recently fallen, on the grounds that they would have an unacceptable cost in terms of their body image:

No, no, no, no, no, no ... Nobody would go around with padding.

I'm big enough as it is- they'd make me look bigger I should think.

Not unless it was absolutely essential ... You know, you're struggling with the fact that your body is getting older anyway, really struggling with that sometimes.

Specific pieces of advice often generated informed debate; for example, about the inadvisability of re- commended calcium-rich bone-strengthening foods for people with high cholesterol, or the merits and limitations of trainers and bifocal spectacles. These debates were combined in many instances with gentle ridicule of the advice, for example, joking about baring the skin to increase vitamin D intake, or getting someone else to do chores (that involve risky activities). Using debate and humour in this way allowed the participants to show that they were not uncritical, passive recipients of lifestyle instructions, but instead were independent and sceptical appraisers of the information provided. Participants also asserted their independence by suggesting alternative forms of exercise or environmental risk reduction in the home. Sometimes humour seemed to be used to distance participants from the threat to their identity potentially posed by messages which implied that they could be considered at risk because of being old and infirm. For instance, jokes were made about which member of the focus group might be the one person out of three aged $>65$ years which the risk information stated would fall each year.

\section{It's good advice-for 'them'}

A very common way of qualifying approval of falls prevention advice was to agree that it was usefulbut only for other people who were in need of it. A younger female participant (aged 67 years) stated that if she received such information 'I'd probably think that's for old ladies [laughs] not for me.' However, this reaction was by no means confined to the younger participants; for example, a male participant aged 79 years and living in sheltered accommodation commented that he and his wife ignored information about falls prevention:

Because we're that much fitter-we don't really take too much notice of it, only for other people, for other disabled or elderly people that we have to watch when we're-we always watch older people anyway.

This same participant later recommended a falls prevention leaflet as important information for the age group of '70 onwards'! Similarly, other participants in their mid-70s who had described recent 
injurious falls nevertheless spoke about the advice as potentially useful for targeting people older than them. Often participants defined themselves as nonfallers, and hence not a suitable target for this advice, because they attributed their falls to an immediate and circumscribed cause-such as temporary inattention or illness-rather than to a persisting vulnerability. For example, a male participant aged 81 years, who defined himself as a non-faller despite having fallen out of bed four times in the previous 8 months, again used humour gently to ridicule the idea that he might benefit from falls prevention advice:

If they did [offer advice] I wouldn't listen to it. In one ear and out the other ... I mean one person said to me 'You should go and see the doctor', but I said 'Well, what can he do?', 'Well, he can talk to you, you know'. I said 'What, when I'm in bed?' ... I'm not saying I'm not concerned about it, but if it kept up weekly, you know, once a week, something like that, then I would go to the doctor's.

One younger female participant clearly indicated that conceding that falls prevention advice might be relevant to her (which she did not) would be humiliating:

I wouldn't go for that [advice] because it didn't apply to me in any shape or form. Is there a bit of pride, is there a bit of 'Well, you know, I'm not there yet?'

\section{Falls prevention advice is not needed, wanted or helpful}

One of the most frequent comments from all participants was that some or all of the advice on falls prevention was essentially just common sense, and therefore not necessary. The steps that should be taken to minimize hazards were viewed as widely known or obvious, while awareness of falling risk was regarded as an inevitable consequence of experiencing decline in physical capabilities. In this context, falls prevention advice could appear patronizing and even unintentionally insulting: one male participant aged 71 years complained that:

It can make you feel-somebody producing the leaflets here-that these people here are senile and they just don't have any common sense and they need to be told everything.

Another male participant (aged 72 years) who had fallen in the past year nevertheless also felt that:

What you get is that they [the authors of the leaflets] are talking to somebody here who they think is senile. The brain is going as well as the arms and the legs ... You got to tell these poor old things what to do, you know, like it's as though we haven't got any sense at all.

Part of the objection to some falls-related advice concerned the tone adopted in leaflets. Often advice was viewed as presented in an overly didactic, directive manner. The participant quoted above explained that:

The leaflet fails to recognise that you're talking to people who are individuals and who are individuals who have a lot of experience of life, are people who appreciate your advice [general laughter among focus group members] but let's have it in a polite way and recognise that, hey, you know, I'm not somebody who is just a moron, that I can understand what's good advice and what isn't and I really don't need your directive to tell me so.

A younger, female participant who had fallen in the past year nevertheless also stated frankly that:

I'm doing all those things now, I'm actually doing them, so I don't feel that I need to be told ... I don't like being told.

Similarly, a female participant living in sheltered accommodation explained that such advice could mar the precious freedom that was a benefit of reaching retirement age:

The older you get the less you want to be told what to do ... because people get to the age of 65 and they know what they are doing, they don't 
need to be told what to do ... There's enough to think about when you're over 65 and you are freelance and you can do what you want to do and you certainly don't want to think about that [falling] unless it's happening to you at that time. No, I would screw that [advice leaflet] up if that was me.

However, it was not solely the manner in which advice was given that was perceived as a problem. The discussion of falls risk was seen by some people as potentially anxiety provoking. For example, one male participant who had not fallen recently and was aged only 69 years nevertheless confessed in the privacy of an interview that:

' 1 in 3' [people over 65 have fallen] Incredible, wonder where they get that? ... this one's the same 'Have you fallen and hurt yourself in the past year'-slipping's frightening, put's the wind up me when they say that, wonder what qualifies as a fall, wonder what they, is that, is it as bad as I'm thinking it is?

Moreover, the risk reduction measures suggested were sometimes viewed as equally detrimental to lifestyle and identity as falling itself. A male participant aged 72 years, who had fallen in the past year, rejected falls prevention advice because:

If you start being so careful about everything you do you turn out to be a doddery old person and that's the last thing you want, and it's the last thing you want is for people to say 'be careful, do this'-we don't want to.

Similarly, a female participant aged 78 years apologetically explained that:

At my age the last thing I want to do is, every time I want-'I've got to be careful, I mustn't step there'. I'm sorry, you know, you just don't want to be thinking all the time. I mean I'm finding now that because I've just had a fall, it takes your confidence away, there's nothing worse than that ... The last thing you want as you get older is to be told that you've got to be conscious every time you go out and might fall, you don't want that, otherwise your life's gone.
I mean, it's hard to explain, but you're not conscious of getting older and you don't want to be reminded of that.

Advice to ask for assistance rather than undertake risky activities was also seen by some participants as an unacceptable loss of independence and selfconfidence. For example, one female participant aged 82 years, who said that her husband would not allow her to stand on a stool to clean the windows, simply did this when her husband was away, because:

I've got a horror of having to reach the day when I've got to rely on someone else.

One of the most common objections to provision of falls prevention advice was the view that falling is inevitable and cannot be prevented. This view may have reflected a genuinely fatalistic attitude in many cases. However, it also appeared to act as a defence against potential accusations of partial responsibility for falling. In this respect, falls prevention advice could be seen as implying that older people could do more to avoid falling, and so are partly to blame if they do fall. For example, one 80-year-old participant defensively argued that:

I don't know how you can be told how to prevent falling. You don't do it on purpose ... it just happens, this is it, you could be in any circumstance at all and it would happen, so what advice anybody could give you?

\section{Discussion}

Our study uncovered a revealing combination of widespread acknowledgement of the potential usefulness of falls prevention advice in principle, together with frequent rejection of that advice by our participants as unnecessary, irrelevant or inappropriate for them. Denial of the personal relevance of falls prevention advice is sometimes taken literally by health professionals as ignorance of the real risk, and hence as evidence for the need for more health education [26]. For example, in Australia the Commonwealth Department of Health 
and Aged Care [27] concluded that 'there is a need to diminish the level of "rationalising away" that exists in relation to having a fall' (p. 20). However, it seems clear that most of the people in our study were only too well aware of their likelihood of falling, but nevertheless refused to accept that they should be defined as, or behave as, potential 'fallers'. In doing so, they explicitly rejected a number of unwelcome connotations of the concept of 'falls prevention advice'; that they needed to be given advice about how to manage their own lives; that they should constantly dwell on and anticipate the limitations of their physical capabilities and that they should prioritize safety over other values such as personal dignity, identity and autonomy. Almost all our participants were previously unaware of the benefits of strength and balance training exercises, a method of falls prevention that they welcomed because it was viewed as promoting independent activity.

Although our participants had generally not been offered or taken part in falls prevention programmes, similar observations have emerged from studies based on falling prevention clinics or programmes. In an Australian study, $80 \%$ of women on a geriatric ward following hip fracture due to falling stated that they would not wear hip protectors since they were not at risk; they suggested that hip protectors were more suitable for elderly and nervous people [28]. Ballinger and Payne [29] found that whereas health professionals saw patients' problems in terms of reducing physical risk, patients were concerned chiefly with threats to their social identity and relationships. Simpson et al. [30] found that some older people viewed interventions to reduce risks in the home as intrusive interference, and Clemson et al. [31] noted that women preferred to make their own decisions about an acceptable level of risk of falling.

\section{Implications for promoting falls prevention}

For health promoters, a possible response to denial of falls risk is to redouble efforts to educate people about their real vulnerability, but it is clear that this strategy could prove counterproductive if by de- nying risk older people are simply asserting their right to independence and dignity. In contrast, it has been suggested that it may be best to abandon advice on risk reduction altogether, and replace it with promotion of activities that enhance fitness, balance and mobility [17]. This emphasis on balance improvement rather than hazard reduction would be likely to increase confidence in balance rather than provoke anxiety about risk, with potentially beneficial consequences for activity levels [32], which in turn may have a positive effect on physical functioning and falls risk [33]. Messages about how balance and mobility could be improved were usually regarded as useful and relevant by our participants, and so a lifespan approach to 'improving posture and balance' or 'increasing freedom and confidence in movement' may prove a more attractive goal than 'falls prevention in later life'.

There could nevertheless be benefits to continuing to advise people of the need and potential to reduce their falls risk. Acceptance that falling risk is a subject that should never be raised might paradoxically increase the stigma associated with it, and the anxiety, shame, isolation and helplessness of people who nonetheless know from their own experience that they may fall. Moreover, research indicates that it may be difficult to persuade older people to undertake physical exercise if they do not perceive an immediate and pressing need and benefit, such as reducing a high personal risk of falling [30, 34]. In addition, some studies have indicated that home hazard reduction may reduce falls [10], particularly if combined with exercise, but if falls risk is a subject that cannot be mentioned then no advice on hazard reduction can be given. Perhaps management of falls risk could be portrayed more acceptably as a constructive rather than purely defensive activity. For example, it might be possible to focus on the positive benefits of reducing medication or making the home environment more convenient, rather than simply emphasizing the need to engage in these measures to avoid falling.

\section{Recommendations for future research}

While qualitative methods can reveal individuals' views of health promotion messages, quantitative 
methods are necessary to determine the prevalence of these views and their relative influence on behaviour. It would therefore be useful to determine the prevalence of the attitudes expressed by our participants, and to directly test the extent to which they are related to low uptake of interventions. Future research could also build on these qualitative findings to develop and experimentally evaluate the relative acceptability and effectiveness of advice and interventions for older people that emphasize enhancing independent living and quality of life rather than—or as well as—reducing falls risk.

\section{Acknowledgements}

This research was commissioned and funded by the charity Help the Aged. We wish to thank all of the organizers of the participating centres and clubs who were so helpful with the recruitment process, Sam Nyman for carrying out two of the focus groups with us and of course all the people who took part in the study.

\section{References}

1. Bruce DG, Devine A, Prince RL. Recreational physical activity levels in healthy older women: the importance of fear of falling. $J$ Am Geriatr Soc 2002; 50: 84-9.

2. Cumming RG, Salkeld G, Thomas M et al. Prospective study of the impact of fear of falling on activities of daily living, SF-36 scores, and nursing home admission. J Gerontol A Biol Sci Med Sci 2000; 55: M299-305.

3. Delbaere K, Crombez G, Vanderstraeten G et al. Fearrelated avoidance of activities, falls and physical frailty. A prospective community-based cohort study. Age Ageing 2004; 33: 368-73.

4. Howland J, Lachman ME, Peterson EW et al. Covariates of fear of falling and associated activity curtailment. Gerontologist 1998; 38: 549-55.

5. Murphy SL, Williams CS, Gill TM. Characteristics associated with fear of falling and activity restriction in communityliving older persons. J Am Geriatr Soc 2002; 50: 516-20.

6. Yardley L, Smith H. A prospective study of the relationship between feared consequences of falling and avoidance of activity in community-living older people. Gerontologist 2003; 42: 17-23.

7. Health Education Authority. Physical Activity and the Prevention and Management of Falls and Accidents Among Older People: A Framework for Practice. London: Health Education Authority, 1999.
8. Todd CJ, Freeman CJ, Camilleriferrante C et al. Differences in mortality after fracture of hip: the East Anglian audit. Br Med J 1995; 310: 904-8.

9. American Geriatrics Society, British Geriatrics Society, American Academy of Orthopaedic Surgeons Panel on Falls Prevention. Guidelines for the prevention of falls in older persons. J Am Geriatr Soc 2001; 49: 664-72.

10. Chang JT, Morton SC, Rubenstein LZ et al. Interventions for the prevention of falls in older adults: systematic review and meta-analysis of randomized controlled trials. $\mathrm{Br} \mathrm{Med} \mathrm{J}$ 2004; 328: 680-3.

11. Gillespie LD, Gillespie WJ, Robertson MC et al. Interventions for preventing falls in elderly people (Cochrane Review). In: The Cochrane Library. London: Update Software, 2001.

12. Skelton D, Todd C. What are the Main Risk Factors for Falls Amongst Older People and What are the Most Effective Interventions to Prevent These Falls? How Should Interventions to Prevent Falls be Implemented? Copenhagen: Health Evidence Network Synthesis, World Health Organisation, 2004.

13. Robertson MC, Devlin N, Gardner MM et al. Effectiveness and economic evaluation of a nurse delivered home exercise programme to prevent falls. 1 randomised controlled trial. Br Med J 2001; 322: 697-701.

14. Stevens M, Holman CDJ, Bennett N et al. Preventing falls in older people: outcome evaluation of a randomized controlled trial. J Am Geriatr Soc 2001; 49: 1448-55.

15. Day L, Fildes B, Gordon I et al. Randomised factorial trial of falls prevention among older people living in their own homes. Br Med J 2002; 325: 128-31.

16. Fabacher D, Josephson K, Pietruszka F et al. An in-home preventive assessment program for independent older adults: a randomized controlled trial. J Am Geriatr Soc 1994; 42: 630-8.

17. Health Education Board for Scotland. The Construction of the Risks of Falling in Older People: Lay and Professional Perspectives. Available at: http://www.hebs.scot.nhs. uk/topics/accidents. Accessed:1 October 2003.

18. Minichiello V, Browne J, Kendig H. Perceptions and consequences of ageism: views of older people. Ageing Soc 2000; 20: 253-78.

19. Weeks LE, Roberto KA. The impact of falls on quality of life: empowering older women to address falls prevention. Qual Ageing 2003; 4: 5-13.

20. Woodhead G, Calnan M, Dieppe P et al. Dignity in old age: what do older people in the United Kingdom think? Age Ageing 2004; 33: 165-70.

21. Kingston P. Falls in later life: status passage and preferred identities as a new orientation. Health 2000; 4: 216-33.

22. McInnes E, Askie L. Evidence review on older people's views and experiences of falls prevention strategies. Worldviews Evid Based Nurs 2004; 1: 20-37.

23. Yardley L, Todd C. Encouraging Positive Attitudes to Falls in Later Life. London: Help the Aged, 2005.

24. Joffe H, Yardley L. Content and thematic analysis. In: Marks D, Yardley L (eds). Research Methods for Clinical and Health Psychology. London: Sage, 2004, 56-68.

25. Strauss A, Corbin J. Basics of Qualitative Research: Grounded Theory Procedures and Techniques. Newbury Park: Sage, 1990. 


\section{Older people's views of falls prevention advice}

26. Braun BL. Knowledge and perception of falls-related risk factors and fall-reduction techniques among communitydwelling elderly individuals. Phys Ther 1998; 78: 1262-76.

27. Commonwealth Department of Health and Aged Care. National Falls Prevention for Older People Initiative "Step Out With Confidence". Canberra: Commonwealth of Australia, 2001.

28. Cameron ID, Quine S. External hip protectors: likely noncompliance among high risk elderly people living in the community. Arch Gerontol Geriatr 1994; 19: 273-81.

29. Ballinger C, Payne S. Falling from grace or into expert hands? Alternative accounts about falling in older people. $\mathrm{Br}$ J Occup Ther 2000; 63: 573-9.

30. Simpson J, Darwin C, Marsh N. What are older people prepared to do to avoid falling? A qualitative study in London. Br J Community Nurs 2003; 8: 133-9.
31. Clemson L, Cusick A, Fozzard C. Managing risk and exerting control: determining follow through with falls prevention. Disabil Rehabil 1999; 21: 531-41.

32. Tennstedt S, Howland J, Lachman $\mathrm{M}$ et al. A randomized controlled trial of a group intervention to reduce fear of falling and associated activity restriction in older adults. J Gerontol B Psychol Sci Soc Sci 1998; 53: 384-92.

33. Campbell AJ, Spears GF, Borrie MJ. Examination by logistic regression modelling of the variables which increase the relative risk of elderly women falling compared to elderly men. J Clin Epidemiol 1990; 43: 1415-20.

34. O'Brien Cousins S. "My heart couldn't take it": older women's beliefs about exercise benefits and risks. J Gerontol B Psychol Sci Soc Sci 2000; 55: 283-94.

Received on February 16, 2005; accepted on December 20, 2005 